\title{
Pituitary spindle cell oncocytoma: illustrative case
}

\author{
Taha M. Taka, BS, ${ }^{1}$ Chen Yi Yang, BS, ${ }^{1}$ Joshua N. Limbo, ${ }^{1}$ Alvin Y. Chan, MD, ${ }^{1}$ Jordan Davies, MD, ${ }^{1}$ Edward C. Kuan, MD, MBA, ${ }^{2}$ \\ Scott G. Turner, MD, ${ }^{3}$ and Frank P. K. Hsu, MD, PhD ${ }^{1}$
}

Departments of ${ }^{1}$ Neurological Surgery, ${ }^{2}$ Otolaryngology, and ${ }^{3}$ Neuro-Oncology, University of California, Irvine, Orange, California

BACKGROUND Spindle cell oncocytoma (SCO) of the pituitary gland is an extremely rare nonfunctional World Health Organization grade I tumor. SCOs are often misdiagnosed as nonfunctional pituitary adenomas on the basis of preoperative imaging. They are often hypervascular and locally adherent, which increases hemorrhage risk and limits resection, leading to increased risk of recurrence. The authors report a case of SCO treated at their institution and provide a review of the current literature.

OBSERVATIONS SCO of the pituitary gland can be a rare cause of progressively growing pituitary tumors that presents similarly to nonfunctional pituitary adenoma. Endoscopic transsphenoidal resection of the tumor by a multidisciplinary team allowed total resection despite local adherence of the tumor. Postoperatively, the patient's visual symptoms improved with persistence of secondary adrenal insufficiency and secondary hypothyroidism.

LESSONS Careful resection is needed due to SCO's characteristic hypervascularity and strong adherence to minimize local structure damage. Longterm follow-up is recommended due to the tendency for recurrence.

https://thejns.org/doi/abs/10.3171/CASE21356

KEYWORDS sella; pituitary; oncocytoma; skull base surgery

Spindle cell oncocytoma (SCO) is an extremely rare nonfunctional neoplasm of the pituitary gland. It was first reported in a case series in 2002 by Roncaroli et al.. ${ }^{1}$ and since then, they have been included in the 2007 World Health Organization (WHO) tumor classification of the central nervous system. Since the first reporting in 2002 , only 81 total cases have been reported in the literature. Although the cause of SCOs remains unclear, previous literature has proposed the folliculostellate cells of the adenohypophysis as the possible origin. Originally, SCO of the pituitary was described with the following characteristics: (1) many fascicles of spindle cells with an eosinophilic, granular cytoplasm, and numerous mitochondria; (2) no expression of pituitary hormones and synaptophysin; (3) immunoreactivity to vimentin, epithelial membrane antigen, S-100 protein, and galectin-3; and (4) lack invasion and demonstrated low proliferative activity. ${ }^{3}$ SCOs are generally difficult to diagnose or are misdiagnosed preoperatively based on imaging alone due to the similarities with nonfunctional pituitary adenomas as well as the relatively rare presentation of $\mathrm{SCO}$. Here we report a patient who presented with bitemporal hemianopsia and was found to have SCO.
In addition, we provide an extensive review of the literature to aid in managing this rare disease.

\section{Illustrative Case}

A 75-year-old male with a previously known asymptomatic pituitary mass presented to the neurosurgery clinic 4 years after initial radiographic tumor detection with 1 month of peripheral visual impairments. His past medical history was significant for normal-pressure hydrocephalus that was treated with lumboperitoneal shunt placement, which, upon continued treatment and monitoring, allowed the incidental detection and periodic tracking of pituitary mass size. In addition, the patient had a history of a prior left thalamic stroke, Parkinson's disease, and atrial fibrillation treated with $81 \mathrm{mg}$ of aspirin daily. His physical examination was largely unremarkable, and his visual field assessment revealed bitemporal hemianopsia. A pituitary hormone profile revealed decreased follicle-stimulating hormone), luteinizing hormone, testosterone, thyroid-stimulating hormone, and free thyroxine and was suggestive of hypopituitarism. Computed tomography and magnetic resonance imaging (MRI) showed that the

ABBREVIATIONS MRI = magnetic resonance imaging; $\mathrm{SCO}=$ spindle cell oncocytoma; $\mathrm{WHO}=$ World Health Organization . INCLUDE WHEN CITING Published October 4, 2021; DOI: 10.3171/CASE21356.

SUBMITTED June 19, 2021. ACCEPTED June 30, 2021.

(c) 2021 The authors, CC BY-NC-ND 4.0 (http://creativecommons.org/licenses/by-nc-nd/4.0/). 

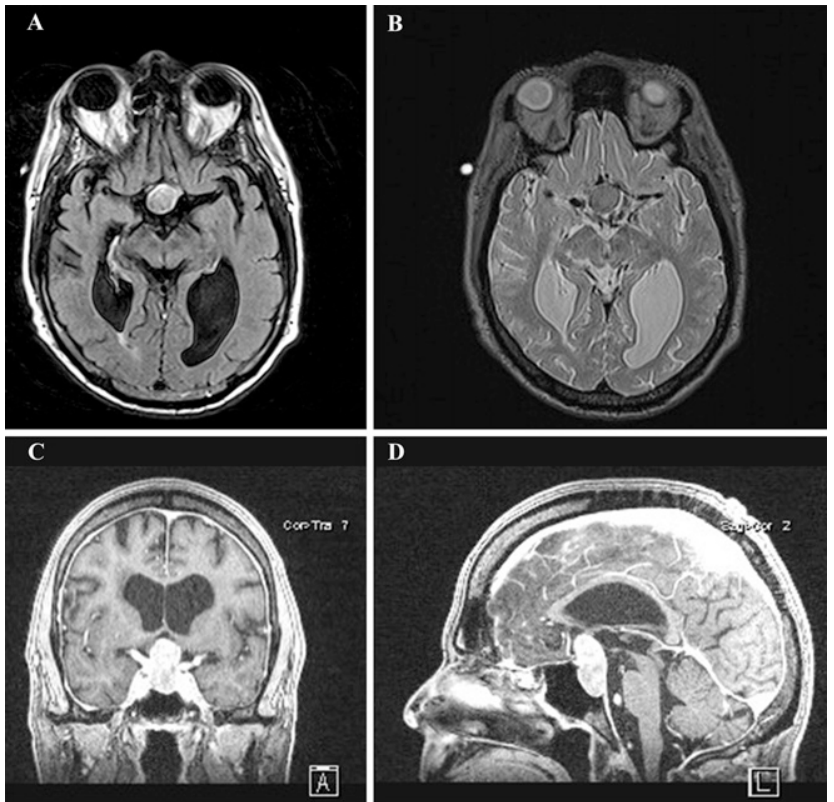

FIG. 1. Preoperative MRI scans of the patient 2 days before scheduled surgery. A: An axial T2 fluid-attenuated inversion recovery image. B: An axial T2-weighted three-dimensional image. C: A coronal image. D: A sagittal image. The enhancing intra- and suprasellar tumor mass can be seen around the center of all four images near the pituitary location and was measured to be $1.5 \times 1.6 \times 3.1 \mathrm{~cm}$.

intra- and suprasellar tumor mass measured $1.5 \times 1.6 \times 3.1 \mathrm{~cm}$, which was larger than before (Fig. 1).

The patient underwent resection of the tumor via an endoscopic transsphenoidal approach. Intraoperatively, the tumor within the sella was found to be fibrous and adherent to the intrasellar dura, with gross invasion of the sellar diaphragm. The tumor was completely resected in piecewise fashion, and the diaphragm was also partially resected, given tumor invasion. A high-flow cerebrospinal fluid leak was encountered intraoperatively, which was subsequently repaired using collagen matrix and a pedicled, vascularized nasoseptal flap.

Postoperative imaging showed decompression of the optic chiasm with no definite residual tumor (Fig. 2). After an uneventful postoperative period, the patient was discharged on the fourth postoperative day.
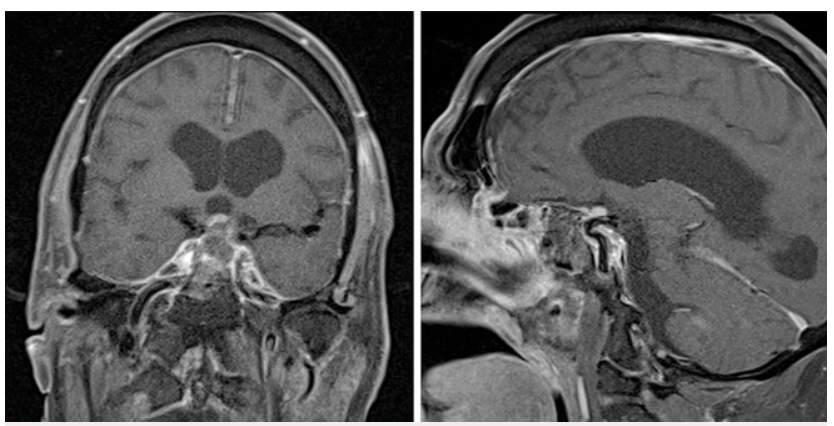

FIG. 2. MRI scan of the patient 1 day postoperatively. The left and right images present a coronal image and sagittal image, respectively. There was no midline shift or herniation; however, residual small areas of suprasellar enhancement and persistent deformity of the anterior third ventricle can be seen in both images.
Follow-up on the eighth postoperative day showed improvement of peripheral vision. Postoperative laboratory test results were significant for secondary adrenal insufficiency and secondary hypothyroidism, with no diabetes insipidus observed.

One month postoperatively, the patient experienced an accidental fall, resulting in a subdural hematoma. The patient is otherwise healthy, but his vision has declined after the fall. He currently experiences left central vision loss and right temporal hemianopia; however, this is still subjectively improved compared with his symptoms before resection of his SCO. The patient experiences no major sinonasal infections or complaints postoperatively and is followed with serial MRI scans every 2 months.

\section{Discussion}

We describe the clinical course, resection, and postoperative period of SCO of the pituitary along with a literature review of case reports of SCO presentation and treatment. Although initially the mass is often misdiagnosed, intraoperative characteristic findings of hypervascularity and local adherence point toward an SCO diagnosis. Total resection of the tumor was achieved with improvement of visual symptoms and persistence of secondary adrenal insufficiency and secondary hypothyroidism.

\section{Observations}

SCO of the pituitary is a rare and unique pituitary tumor of the sella turcica, and they are radiologically indistinguishable from other nonfunctioning pituitary macroadenomas and thus can often be misdiagnosed. ${ }^{1}$ It is believed that this neoplasm of the anterior pituitary stems from the folliculostellate cells of the adenohypohysis and presents with a benign and slowly progressive clinical course that is categorized according to WHO grade I tumors. ${ }^{2,3}$ Compared with other pituitary adenomas, SCOs are highly vascularized tumors, and thus the resection of these tumors presents a great challenge. Due to their vascularity, local invasions can occur from the sella to the cavernous sinus or the sphenoid sinus. ${ }^{3-5}$ Although SCOs do not present with immunoreactivity to either pituitary hormones or neuroendocrine markers (e.g., synaptophysin, chromogranin), they possess a distinct immunohistochemical and ultrastructural profile. Immunohistochemically, SCOs stain positive for vimentin, S-100, epithelial membrane antigen, and galectin-3., Ultrastructurally, SCOs appear in a spindled shape with eosinophilic cytoplasm full of mitochondria rich in lamellar cristae. ${ }^{6,7}$

SCO commonly presents in adults with slow but progressive symptoms. Our literature review of 81 cases (Table 1) from 2002 to 2021 determined that the most common presenting symptoms are visual deficits $(67.9 \%)$, hypopituitarism $(37.0 \%)$, headache $(33.3 \%)$, and nausea $(11.1 \%))^{1,3-39}$ The tumor commonly occurs in adults with an average onset age of 56.2 years (range of 8-80 years). A distribution of the patients by decade of life reveals a skew toward increased incidence in older age, where $75 \%$ of patients are over 50 years of age (Fig. 3). Of the 55 patients who presented with visual deficits, 20 had bitemporal hemianopsia. Although most cases presented with a progressively slow onset of symptoms, Osman \& Wild ${ }^{9}$ presented a case of a patient who developed acute symptoms secondary to intratumoral hemorrhage with extension into the ventricles, much like pituitary apoplexy. ${ }^{9}$

On imaging, SCO generally presents as a sellar mass with or without suprasellar extension. Although the vast majority of the literature describes SCO imaging findings as being indistinguishable 
TABLE 1. Differences in pituitary SCO presentation and recurrence in male and female patients in the literature

\begin{tabular}{|c|c|c|c|}
\hline & Male $(n=45)$ & Female $(n=36)$ & Total $(\mathrm{N}=81)$ \\
\hline Percentage of total patients & 55.6 & 44.4 & 100.0 \\
\hline Average age w/ SD (yrs) & $57.8 \pm 15.0$ & $54.2 \pm 14.4$ & $56.2 \pm 14.7$ \\
\hline \multicolumn{4}{|l|}{ Symptoms } \\
\hline Nausea $(\%)$ & 8.9 & 13.9 & 11.1 \\
\hline Visual deficits (\%) & 73.3 & 61.1 & 67.9 \\
\hline Headache (\%) & 33.3 & 33.3 & 33.3 \\
\hline Hypopituitarism (pan/partial) (\%) & 26.7 & 22.2 & 24.7 \\
\hline Average tumor volume $\mathrm{w} /$ range $\left(\mathrm{cm}^{3}\right)$ & $11.3(0.42-6.5)$ & $23.0(3.0-85.8)$ & $15.4(0.42-85.8)$ \\
\hline Rate of hypervascularity (\%) & 35.6 & 24.4 & 33.3 \\
\hline Full resection (\%) & 25.6 & 54.8 & 38.6 \\
\hline Percentage of cases where RT was used & 42.2 & 22.2 & 33.3 \\
\hline Recurrence rate $(\%)$ & 22.2 & 25.0 & 23.5 \\
\hline Average time until recurrence $\mathrm{w} /$ range (mos) & $19.3(1-77)$ & $45.7(3-120)$ & $32.5(1-120)$ \\
\hline
\end{tabular}

$\mathrm{RT}=$ radiotherapy.

from nonfunctional pituitary adenomas, a recent report by Hasiloglu et al. proposed differences for distinguishing the two. ${ }^{11}$ SCOs on MRI are usually inseparable from the pituitary gland and typically present with extensive compression of the optic chiasm, pituitary stalk, and cavernous sinus. On the one hand, on T1-weighted MRI, SCO appears isointense to the cortex and heterogeneously enhances after contrast administration. On the other hand, pituitary adenomas typically present with isointense to hypointense changes with homogeneous enhancement after contrast administration. Hasiloglu et al. considered the millimetric hypointense foci and linear signal void as the most distinguishing features of SCOs compared with pituitary adenomas. The authors hypothesized that the hypointense foci areas are hemosiderin deposits, whereas the linear signal void is likely a vascular structure. ${ }^{11}$

In our literature review, $84 \%$ of SCO patients (68 of 81) were treated with or had a history of transsphenoidal surgery, whereas $13.6 \%$ were treated with or had a history of previous craniotomy. For highly extensive tumors, craniotomy may be preferable in certain cases because it allows improved visualization and control of surrounding neurovascular structures. ${ }^{10}$ However, because SCOs are frequently assumed to be pituitary adenomas on preoperative imaging, transsphenoidal surgery is conventionally used as the first

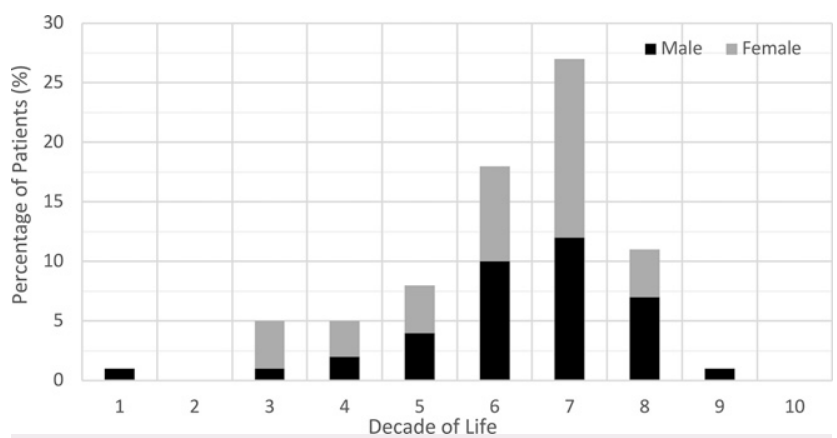

FIG. 3. Distribution of SCO occurrence throughout the decades of life in male and female patients. choice. ${ }^{10}$ Partial resection is common because of the adherent nature of SCOs, and residual tumor is usually treated with radiotherapy. In our review of the literature, $36.8 \%$ of patients (25 of 68) were treated with radiotherapy as either adjuvant therapy or for recurrence. , $^{3,6,8,9,12,13,40,41}$ The efficacy and indications for radiotherapy are unclear, given the rarity of the disease, and there are inadequate data to determine whether the recurrence rate is modified with radiotherapy. ${ }^{8,23}$

Intraoperatively, the hypervascularity of SCO may increase the risk of significant intraoperative tumor bleeding, sometimes necessitating subtotal tumor resection. ${ }^{3,9,16,42}$ Borges et al. noted that there were a high number of cases with excessive intraoperative bleeding. ${ }^{42}$ Our literature review revealed this trend to be similar to cases today, because $33 \%$ of case reports have noted the hypervascularity of SCO. Ultimately, the inability to achieve gross total resection may be limited by hypervascularity and extensive adhesion of the tumor to local structures. In a single case, Tariciotti et al. used preoperative embolization before reresection of an SCO that helped control intraoperative bleeding, though the pathology was known before surgery, given recurrent tumor status. ${ }^{21}$

Postoperatively, continuous and regular follow-up of SCOs should be prioritized. Our review determined an average 36.8-month postoperative follow-up period for patients with SCO. Due to the large proportion of partial resections in SCO and the progressive nature of $\mathrm{SCO}$, recurrence is common. Of the cases reported in the literature, we found that recurrence occurred in $23.5 \%$ of cases, and time to recurrence ranged from 1 to 120 months postoperatively. If recurrence does occur, its presentation closely parallels the original tumor presentation with visual deficits, hypopituitarism, and/or headache. Regardless of recurrence, on the one hand, patient visual symptoms and headache often improve postoperatively, either progressively or immediately, due to decreased mass effect of the tumor. ${ }^{8,16,40,42,43}$ On the other hand, hypopituitarism is one the most common complications of pituitary surgery postoperatively, which can occur transiently or permanently and may require hormone replacement with long-term endocrinological treatment. ${ }^{44}$ In addition, surgical intervention with pituitary tumors poses inherent postoperative risk due to the 
location and can lead to meningitis, hydrocephalus, cranial nerve palsy, visual worsening, and hemiparesis. ${ }^{18}$

Patients with SCO present both a diagnostic and a therapeutic challenge. Their nonspecific presentation of visual deficits, headache, and/or hypopituitarism and rarity often lead to misdiagnosis. In addition, resection is complicated by the hypervascularity and hyperadherence of the tumor. This reality, coupled with the propensity of the progressive growth of the tumor, leads to a high rate of recurrence; therefore, a long-follow-up period is recommended postoperatively.

\section{Lessons}

This case report highlights the clinical presentation and surgical approach to treat SCO of the pituitary. Due to the hypervascularity and strong adherence of this tumor, careful resection is recommended to minimize damage to local structures. In addition, longterm follow-up is highly recommended because these tumors have a high tendency to recur.

\section{References}

1. Roncaroli F, Scheithauer BW, Cenacchi G, et al. 'Spindle cell oncocytoma' of the adenohypophysis: a tumor of folliculostellate cells? Am J Surg Pathol. 2002;26(8):1048-1055.

2. Fuller GN, Scheithauer BW. The 2007 Revised World Health Organization (WHO) Classification of Tumours of the Central Nervous System: newly codified entities. Brain Pathol. 2007;17(3):304-307.

3. Fujisawa H, Tohma Y, Muramatsu N, Kida S, Kaizaki Y, Tamamura $\mathrm{H}$. Spindle cell oncocytoma of the adenohypophysis with marked hypervascularity. Case report. Neurol Med Chir (Tokyo). 2012;52(8):594-598.

4. Kloub O, Perry A, Tu PH, Lipper M, Lopes MB. Spindle cell oncocytoma of the adenohypophysis: report of two recurrent cases. Am J Surg Pathol. 2005;29(2):247-253.

5. Borota OC, Scheithauer BW, Fougner SL, Hald JK, Ramm-Pettersen J, Bollerslev J. Spindle cell oncocytoma of the adenohypophysis: report of a case with marked cellular atypia and recurrence despite adjuvant treatment. Clin Neuropathol. 2009;28(2):91-95.

6. Giantini Larsen AM, Cote DJ, Zaidi HA, et al. Spindle cell oncocytoma of the pituitary gland. J Neurosurg. 2018;131(2):517-525.

7. Matyja E, Maksymowicz M, Grajkowska W, Olszewski W, Zielinski G, Bonicki W. Spindle cell oncocytoma of the adenohypophysis - a clinicopathological and ultrastructural study of two cases. Folia Neuropathology. 2010;48(3):175-184.

8. Dahiya S, Sarkar C, Hedley-Whyte ET, et al. Spindle cell oncocytoma of the adenohypophysis: report of two cases. Acta Neuropathol. 2005;110(1):97-99.

9. Osman M, Wild A. Spindle cell oncocytoma of the anterior pituitary presenting with an acute clinical course due to intraventricular hemorrhage. A case report and review of literature. Am J Case Rep. 2017:18:894-901.

10. Buchfelder M, Schlaffer SM, Zhao Y. The optimal surgical techniques for pituitary tumors. Best Pract Res Clin Endocrinol Metab. 2019;33(2):101299.

11. Hasiloglu Zl, Ure $\mathrm{E}$, Comunoglu $\mathrm{N}$, et al. New radiological clues in the diagnosis of spindle cell oncocytoma of the adenohypophysis. Clin Radiol. 2016;71(9):937.e935-937.e911.

12. Coiré $\mathrm{Cl}$, Horvath $\mathrm{E}$, Smyth HS, Kovacs K. Rapidly recurring folliculostellate cell tumor of the adenohypophysis with the morphology of a spindle cell oncocytoma: case report with electron microscopic studies. Clin Neuropathol. 2009;28(4):303-308.

13. Demssie YN, Joseph J, Dawson T, Roberts G, de Carpentier J, Howell S. Recurrent spindle cell oncocytoma of the pituitary, a case report and review of literature. Pituitary. 2011;14(4):367-370.
14. Mu Q, Yu J, Qu L, et al. Spindle cell oncocytoma of the adenohypophysis: two case reports and a review of the literature. Mol Med Rep. 2015;12(1):871-876.

15. Custodio PJ, Jho D, Pu C, Gordon M, Donangelo I. Spindle cell oncocytoma of the pituitary presenting with severe hyponatremia. AACE Clinical Case Reports. 2016;2(3):237-243.

16. Billeci D, Marton E, Giordan E, Carraro V, Ronzon M, Rossi S. Spindle cell oncocytoma: Report of two cases with massive bleeding and review of the literature. J Clin Neurosci. 2017;39:39-44.

17. Sali A, Epari S, Tampi C, Goel A. Spindle cell oncocytoma of adenohypophysis: Review of literature and report of another recurrent case. Neuropathology. 2017;37(6):535-543.

18. Guerrero-Pérez F, Marengo AP, Vidal N, Iglesias P, Villabona C. Primary tumors of the posterior pituitary: A systematic review. Rev Endocr Metab Disord. 2019;20(2):219-238.

19. Akyoldas G, Hergünsel Ö, Özdemir I, Şengöz M, Peker S. Gamma knife radiosurgery for pituitary spindle cell oncocytomas. Clin Neurol Neurosurg. 2019;187:105560.

20. Cole TS, Potla S, Sarris CE, et al. Rare thyroid transcription factor 1-positive tumors of the sellar region: Barrow neurological institute retrospective case series. World Neurosurg. 2019;129:e294-e302.

21. Tariciotti L, Arrichiello A, Fiore G, et al. Arterial embolization and second-look in spindle cell oncocytoma of the pituitary gland: Case report and review of literature. World Neurosurg. 2021;142:87-92.

22. Borg A, Jaunmuktane Z, Dorward N. Tumors of the neurohypophysis: One unit's experience and literature review. World Neurosurg. 2020;134:e968-e978.

23. Hasegawa H, Van Gompel JJ, Oushy SH, et al. A comprehensive study of spindle cell oncocytoma of the pituitary gland: Series of 6 cases and meta-analysis of 85 cases. World Neurosurg. 2021.

24. Yoshida K, Toda M, Akiyama T, et al. Combined endoscopic endonasal and video-microscopic transcranial approach with preoperative embolization for a posterior pituitary tumor. World Neurosurg. 2018;119:201-208.

25. Gupta RK, Batra VV, Singh D, Sharma MC, Kumar V. Is spindle cell oncocytoma a true entity or a variant of pituicytoma? A case report with review of literature. Neurol India. 2018;66(5):1413-1418.

26. Witte HM, Riecke A, Saeger W, et al. Spindle cell oncocytoma of the neurohypophysis with metastasis to the sphenoparietal sinus and immunohistochemical negativity for S100 and epithelial membrane antigen (EMA). Br J Neurosurg. 2018:1-6.

27. Yip CM, Lee HP, Hsieh PP. Pituitary spindle cell oncocytoma presented as pituitary apoplexy. J Surg Case Rep. 2019;2019(6):rjz179.

28. Sollfrank L, Lettmaier S, Erdmann M, Uslu U. Panniculitis under successful targeted inhibition of the MAPK/ERK Signaling pathway in a patient with BRAF V600E-mutated spindle cell oncocytoma of the pituitary gland. Anticancer Res. 2019;39(7):3955-3959.

29. Li Y, Chen SH, Sheinberg D, et al. Imaging characteristics of a hypervascular pituitary spindle cell oncocytoma on magnetic resonance imaging and digital subtraction angiography. World Neurosurg. 2020;133:56-59.

30. Samadian M, Mousavinejad SA, Khoshsirat S, et al. Trans-nasal trans-sphenoidal endoscopic resection of spindle cell oncocytoma of adenohypophysis: The first case report in a child and a review of literature. Asian J Neurosurg. 2020;15(1):210-213.

31. Kong X, Li D, Kong Y, Zhong D. Malignant adenohypophysis spindle cell oncocytoma with repeating recurrences and a high Ki-67 index. Medicine (Baltimore). 2017;96(4):e5657.

32. M. Rafiq N, Kuniak M, Anichini G, Togersen A, H. Kamel M. Spindle cell oncocytoma of the adenohypophysis: 2 case reports of unusual radiological and intra-operative findings. 2017;10:81-85.

33. Xie J, Silverman J, Pu C, et al. Spindle cell oncocytoma of adenohypophysis: Cytogenetics and $\beta$-catenin findings with pathology differential diagnosis and review of the literature. Human Pathology: Case reports. 2017:9:71-75. 
34. Nagata $Y$, Inoshita N, Fukuhara N, Yamaguchi-Okada M, Nishioka $H$, Yamada S. Low-grade glioma of the neurohypophysis: Clinical characteristics and surgical outcomes. World Neurosurg. 2018;114:e1225-e1231.

35. Guadagno E, Cervasio M, Di Somma A, Califano M, Solari D, Del Basso De Caro M. Essential role of ultrastructural examination for spindle cell oncocytoma: Case report of a rare neoplasm and review of the literature. Ultrastruct Pathol. 2016;40(2):121-124.

36. Vajtai I, Sahli R, Kappeler A. Spindle cell oncocytoma of the adenohypophysis: report of a case with a 16-year follow-up. Pathol Res Pract. 2006;202(10):745-750.

37. Alexandrescu S, Brown RE, Tandon N, B Bhattacharjee M. Neuron precursor features of spindle cell oncocytoma of adenohypophysis. Annals of Clinical and Laboratory Science. 2012:42:123-129.

38. Zygourakis CC, Rolston JD, Lee HS, Partow C, Kunwar S, Aghi MK. Pituicytomas and spindle cell oncocytomas: modern case series from the University of California, San Francisco. Pituitary. 2015;18:150-158.

39. Vuong HG, Kondo T, Tran TM, et al. Spindle cell oncocytoma of adenohypophysis: Report of a case and immunohistochemical review of literature. Pathol Res Pract. 2016;212(3):222-225.

40. Ogiwara H, Dubner S, Shafizadeh S, Raizer J, Chandler JP. Spindle cell oncocytoma of the pituitary and pituicytoma: Two tumors mimicking pituitary adenoma. Surg Neurol Int. 2011;2:116.

41. Manoranjan B, Koziarz A, Kameda-Smith MM, Provias JP. Multiple recurrences require long-term follow-up in patients diagnosed with spindle cell oncocytoma of the sella turcica. $J$ Clin Neurosci. 2017;43:134-146.

42. Borges MT, Lillehei KO, Kleinschmidt-DeMasters BK. Spindle cell oncocytoma with late recurrence and unique neuroimaging characteristics due to recurrent subclinical intratumoral bleeding. $J$ Neurooncol. 2011;101(1):145-154.

43. Rotman JA, Kucharczyk W, Zadeh G, Kiehl TR, Al-Ahmadi H. Spindle cell oncocytoma of the adenohypophysis: a case report illustrating its natural history with 8-year observation and a review of the literature. Clin Imaging. 2014;38(4):499-504.

44. Prete A, Corsello SM, Salvatori R. Current best practice in the management of patients after pituitary surgery. Ther Adv Endocrinol Metab. 2017;8(3):33-48.

\section{Disclosures}

Dr. Kuan reported consulting income from Stryker ENT outside the submitted work.

\section{Author Contributions}

Conception and design: Yang, Chan, Davies, Kuan, Turner, Hsu. Acquisition of data: Taka, Yang, Chan, Kuan. Analysis and interpretation of data: Taka, Yang, Kuan. Drafting the article: Taka, Yang, Limbo, Chan. Critically revising the article: Taka, Yang, Limbo, Davies, Kuan, Turner, Hsu. Reviewed submitted version of manuscript Taka, Yang, Limbo, Davies, Kuan, Hsu. Approved the final version of the manuscript on behalf of all authors: Taka. Statistical analysis: Taka. Administrative/technical/material support: Yang, Turner. Study supervision: Kuan, Hsu.

\section{Correspondence}

Taha M. Taka: University of California, Irvine, School of Medicine, Orange, CA. ttaka013@medsch.ucr.edu. 